\title{
Facile mechanical shaking method is an improved isolation approach for islet preparation and transplantation
}

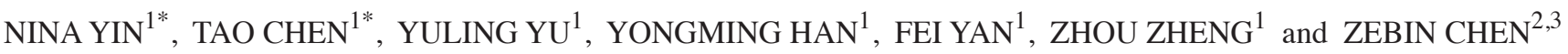 \\ ${ }^{1}$ Department of Anatomy, College of Basic Medicine; \\ ${ }^{2}$ Department of Acupuncture and Moxibustion, College of Acupuncture and Orthopedics; \\ ${ }^{3}$ Hubei Provincial Collaborative Innovation Center of Preventive Treatment by Acupuncture and Moxibustion, \\ Hubei University of Chinese Medicine, Wuhan, Hubei 430065, P.R. China
}

Received September 23, 2015; Accepted September 15, 2016

DOI: $10.3892 /$ etm.2016.3844

\begin{abstract}
Successful islet isolation is crucial for islet transplantation and cell treatment for type 1 diabetes. Current isolation methods are able to obtain 500-1,000 islets per rat, which results in a waste of $\geq 50 \%$ of total islets. In the present study, a facile mechanical shaking method for improving islet yield (up to 1,500 per rat) was developed and summarized, which was demonstrated to be more effective than the existing well-established stationary method. The present results showed that isolated islets have a maximum yield of $1,326 \pm 152$ when shaking for $15 \mathrm{~min}$ for the fully-cannulated pancreas. For both fully-cannulated and half-cannulated pancreas in the presence of rat DNAse inhibitor, the optimal shaking time was amended to $20 \mathrm{~min}$ with a further increased yield of $1,344 \pm 134$ and $1,286 \pm 124$ islets, respectively. Furthermore, the majority of the isolated islets were morphologically intact with a well-defined surface and almost no central necrotic zone, which suggested that the condition of islets obtained via the mechanical shaking method was consistent with the stationary method. Islet size distribution was also calculated and it was demonstrated that islets from the stationary method exhibited the same size distribution as the non-cannulated group, which had more larger islets than the fully-cannulated and half-cannulated groups isolated via the shaking method. In addition, the results of glucose challenge showed that the refraction index of each group was $>2.5$, which indicated the well-preserved function of isolated islets. Furthermore, the transplanted islets exhibited a
\end{abstract}

Correspondence to: Professor Zebin Chen, Hubei Provincial Collaborative Innovation Center of Preventive Treatment by Acupuncture and Moxibustion, Hubei University of Chinese Medicine, 1 Huangjiahu West Road, Hongshan, Wuhan, Hubei 430065, P.R China

E-mail: chenzebin-hbtcm@outlook.com

*Contributed equally

Key words: mechanical shaking method, islet isolation, islet transplantation, type 1 diabetes therapeutic effect after 1 day of transplantation; however, they failed to control blood glucose levels after $\sim 7$ days of transplantation. In conclusion, these results demonstrated that the facile mechanical shaking method may markedly improve the yield of rat islet isolation, and in vitro and in vivo investigation demonstrated the well-preserved function of isolated islets in the control of blood glucose. Therefore, the facile mechanical shaking method may be an alternative improved procedure to obtain higher islet yield for islet preparation and transplantation in the treatment of type 1 diabetes.

\section{Introduction}

Diabetes mellitus is a clinical disorder of intermediary metabolism characterized by hyperglycemia and glycosuria due to the inadequate secretion and/or utilization of insulin, and previous investigation has demonstrated the potential of islet transplantation for the cure for type 1 diabetes with successful islet isolation and preparation (1). One crucial limitation of islets therapy in laboratory research and clinic application is the shortage of islets donations, which is due to the low efficiency of current islet isolation method $(2,3)$. Therefore, high yielding islet isolation is a prerequisite of successful islet transplantation (4).

Over the past 40 years, various methods for the isolation of rat islets have been introduced. Isolation of rat pancreas islets was first described by Lacy and Kostianovsky (5), and various subsequent procedures have been reported for pancreatic islet isolation based on this technique (6). However, the majority of these methods were only able to obtain relatively low islet yields, which resulted in a large number of wasted rat islets (7). Following the application of all of these methods in our laboratory, it was demonstrated that the low isolation efficiency was predominantly due to the inadequate digestion of pancreas tissue. To improve the digestion efficiency, the rat pancreas was either perfused with enzyme solution or cut into pieces before digestion $(8,9)$. However, the commonly used stationary method exhibited poor tissue/enzyme interaction and resulted in inadequate digestion $(10,11)$. Islets were found to attach or become trapped in undigested tissue, which led to a decrease in isolation yield (12). The current well-established stationary method, which involves cannulation through the 
bile duct and Histopaque gradient centrifugation, is able to harvest $500-1,000$ islets from one rat, which is $50 \%$ of the total amount of a rat pancreas $(13,14)$.

In the present study, a mechanical shaking method was established to solve the low efficiency of islet isolation and improve the islet yield. By applying continuous shaking during digestion, the pancreas tissue was adequately digested, which resulted in an improved isolation yield of up to 1,500 islets per rats (50\% more than the well-established stationary method). Notably, the majority of the isolated islets were morphologically intact with a well-defined surface. Furthermore, optimization of the shaking conditions was studied and characterization of the islets demonstrated well-preserved function to control blood glucose in vitro and in vivo. This facile mechanical shaking method markedly improved the yield of islet isolation and is likely to aid islet preparation and transplantation for the treatment of type 1 diabetes.

\section{Materials and methods}

Animals. A total of 296 male Sprague-Dawley (SD) rats (8-12 weeks old), weighing 250-300 g, and 32 C57BL/6 mice (6-8 weeks old), weighing 20-22 g were purchased from the Laboratory Animal Services Center of Hubei University of Chinese Medicine (Wuhan, China). Animals were maintained in a controlled environment (room temperature, $20 \pm 1{ }^{\circ} \mathrm{C}$; relative humidity, $55 \pm 15 \%$; 12 -h light/dark cycle) and permitted ad libitum access to food and water throughout the experiment. All animals were treated in accordance with international ethical guidelines and the National Institutes of Health Guide concerning the Care and Use of Laboratory Animals.

Facile mechanical shaking method. Male SD rats, weighing 250-300 g, were used. Following $\mathrm{CO}_{2}$ euthanasia, $8 \mathrm{ml}$ M199/HEPES buffer digestion solution (Hyclone; GE Healthcare, Logan, UT, USA) supplemented with $0.1 \%$ Liberase (Roche Diagnostics, Indianapolis, IN, USA) was cannulated into the pancreas via the bile duct. The pancreas was subsequently transferred to a 50-ml centrifuge tube (non-cannulated pancreas was cut into $1 \mathrm{~mm}^{2}$ pieces using surgical scissors) and maintained on ice for $30 \mathrm{~min}$. Subsequently, the tube was placed on a rotary shaker (500 rpm; VWR Scientific, San Francisco, CA, USA) in a $37^{\circ} \mathrm{C}$ incubator for 5-35 min. Once all the tissue was digested and the suspension was homogeneous $4^{\circ} \mathrm{C}$ PBS was added to terminate digestion and the sample was centrifuged twice in $4^{\circ} \mathrm{C}$ PBS to remove Liberase $(15 \mathrm{~min}$ at $500 \mathrm{x} \mathrm{g})$. . The digested pancreas was filtered through a $450-\mu \mathrm{m}$ sieve (Sartorius AG, Goettingen, Germany) to remove large particles (mostly non-cannulated pancreas) and the digested pancreas was subsequently suspended in a Histopaque 1077/PBS media gradient (Sigma-Aldrich; Merck Millipore, Darmstadt, Germany), and was centrifuged at $\sim 1,000 \times \mathrm{g}$ for $30 \mathrm{~min}$ at room temperature. Islets trapped on the sieve were obtained by washing the sieve several times with PBS. All islets were purified by the selection of complete and live islets by hand under a light microscope for the following experiments under a light microscope (Thermo Fisher Scientific, Inc., Waltham, MA, USA).
Stationary method. Following cannulation, the pancreas was transferred to a centrifuge tube, maintained on ice for $30 \mathrm{~min}$ and subsequently incubated in a $37^{\circ} \mathrm{C}$ water bath for digestion. Following incubation, the tube was shaken by hand to disrupt the pancreas until the suspension was homogeneous. Subsequently, $4^{\circ} \mathrm{C}$ PBS was added to terminate digestion and drastic shaking was applied 40 times to completely disintegrate the large tissue particles. The remaining procedure was the same as the mechanical shaking method.

Degrees of pancreas perfusion. To verify that the mechanical shaking method was suitable for the pancreas, cannulation was performed in three degrees, including fully-cannulated, half-cannulated and non-cannulated. In the fully-cannulated group, $8 \mathrm{ml}$ media was applied and the pancreas was fully perfused; whereas in the half-cannulated group, $4 \mathrm{ml}$ media was applied and the pancreas was just partially perfused. No media was cannulated into the pancreas in the non-cannulated group.

Addition of inhibitor of caspase-activated DNase (ICAD). Anti-rat ICAD was purchased from Medical and Biological Laboratories, Co., Ltd., (Nagoya, Japan) (15). A total of $1 \mu \mathrm{g} / \mathrm{ml}$ ICAD was added to the digestion media prior to shaking, and the formation of DNA-crosslinking was monitored, as previously described (16).

Islet culture. Isolated islets were cultured in a non-treated Petri dish with an islet density of 5 islets $/ \mathrm{cm}^{2}$. The culture media was RPMI-1640 (Hyclone; GE Healthcare) supplemented with $2.8 \mathrm{mmol}$ glucose, $10 \%$ fetal bovine serum (FBS) and $1 \%$ penicillin and streptomycin (all Gibco; Thermo Fisher Scientific, Inc.) at $37^{\circ} \mathrm{C}$ in humidified air containing $5 \% \mathrm{CO}_{2}$ (17). Prior to each test, the islets were purified and complete and live islets were selected by hand under a light microscope for use in subsequent experiments.

Morphology and size of isolated islets. Following isolation, islet morphology was studied under a light microscope (Thermo Fisher Scientific, Inc.). Islets in good condition are brown in color with a well-identified surface and no necrotic zone in the center. For diameter distribution measurement, 200 islets were randomly chosen and analyzed under a dissection microscope with a fluorescent illuminator equipped with an ocular micrometer with an accuracy of $25 \mu \mathrm{m}$.

Glucose challenge. For the different isolation methods, 100 islets with a diameter of 100-200 $\mu \mathrm{m}$ were selected. Islets were pre-incubated for $1 \mathrm{~h}$ in $5 \mathrm{ml}$ FBS-free RPMI-1640 medium containing low glucose $(2.8 \mathrm{mmol})$ in a 6 -well plate at $37^{\circ} \mathrm{C}$ with $5 \% \mathrm{CO}_{2}$. During the following $3 \mathrm{~h}$, RPMI-1640 medium with $2.8,28$ and $2.8 \mathrm{mmol}$ glucose was added consecutively at each hour, respectively. Following incubation, the medium was collected and stored at $-20^{\circ} \mathrm{C}$ for subsequent insulin concentration determination.

Islet transplantation. Male C57BL/6 mice were utilized for transplantation. To establish insulin-dependent diabetic mice models, normal C57BL/6 mice were treated with $50 \mathrm{mg} / \mathrm{kg}$ streptozotocin (STZ; Sigma-Aldrich; Merck Millipore) via the 
tail veil for 5 consecutive days. The blood glucose levels of all the mice were retested prior to transplantation. Only mice with non-fasted blood glucose levels $>300 \mathrm{mg} / \mathrm{dl}$ for 2 consecutive days were considered diabetic and underwent transplantation. Mice were anesthetized using 3\% isofluorane (AErrane; Baxter, Deerfield, IL, USA) in oxygen and maintained at the same rate throughout the procedure. Prior to transplantation, all islets were immersed in PBS three times to completely remove the culture media. A total of 500 islets were then suspended in $500 \mu \mathrm{l}$ sterile PBS and transferred in a 1-ml syringe. The abdomens of the mice were shaved and sterilized using alcohol and the islets were subsequently injected into the abdominal cavity. The blood glucose levels of treated mice were monitored once every 2 days. A small drop of blood was collected from the tail vein using a lancet and tested using a commercial glucometer (Roche Diagnostics). Mice with blood glucose levels $<200 \mathrm{mg} / \mathrm{dl}$ were considered normoglycemic. Monitoring continued until all mice had returned to a hyperglycemic state (blood glucose levels $>250 \mathrm{mg} / \mathrm{dl}$ ).

Statistical analysis. All results are expressed as the mean \pm standard deviation of data obtained from triplicate experiments. All analyses were performed using SPSS 17.0 statistical analysis software (SPSS, Inc., Chicago, IL, USA). Two-tailed Student's t-test was used for all statistical analyses, with $\mathrm{P}<0.05$ considered to indicate a statistically significant difference.

\section{Results}

Islet yield is improved by the facile mechanical shaking method. Fig. 1 demonstrates a comparison of islet yields from a single rat using the common stationary method and shaking methods. The results indicated that a higher yield of isolated islets was obtained with the facile mechanical shaking method (1,326 \pm 134$)$, as compared with the common stationary method $(906 \pm 128)$, which was an improvement of $\sim 50 \%$ on the isolation yield.

Fully cannulated treatment and the presence of ICAD contributes to an increment of islet yield. To study how shaking time may affect the isolation yield, the pancreas was placed on the shaker for varying periods of time and the different cannulation situations were studied individually. For the fully-cannulated pancreas, as the shaking time increased, the isolation yield exhibited an increasing trend with a maximum yield of $1,346 \pm 137$ when the shaking time was $15 \mathrm{~min}$ (Fig. 2A). When the shaking time increased further, the yield did not increase as expected; instead, a marked reduction was detected due to the formation of DNA-crosslinks. The half-cannulated pancreas exhibited a similar trend to the fully-cannulated pancreas, with a maximum yield of $1,293 \pm 135$ islets when shaken for 15 min (Fig. 2B). However, the non-cannulated pancreas demonstrated a different trend, as the best shaking time was delayed to $20 \mathrm{~min}$, with a maximum yield of $365 \pm 62$ islets (Fig. 2C). This may be due to larger tissues requiring additional time to be digested. One phenomenon noted in all the groups was that further shaking following the maximum yield induced the formation of DNA-crosslinks, which decreased the isolation yield markedly.

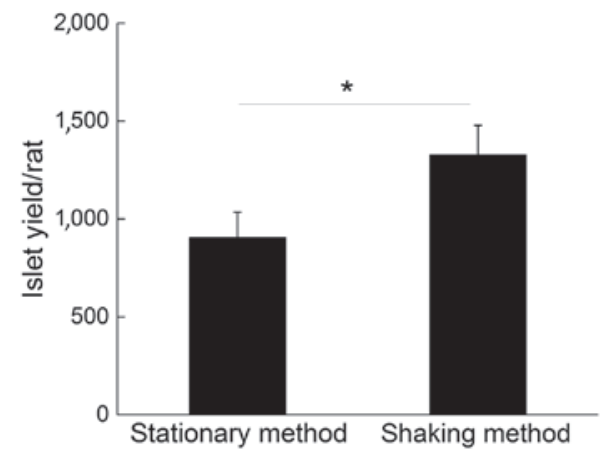

Figure 1. Islet yield isolated via the well-established stationary method and the novel shaking method. The islet yield of isolation from a single rat was compared between the common stationary method and the shaking method. The stationary method was optimized during a previous study and was applied as the control. The only difference between the two methods during the isolation procedure was that facile mechanical shaking was used during digestion in the shaking methods. Data are presented as the mean \pm standard deviation $(\mathrm{n}=8)$. Student's t-test was used for the determination of significance. ${ }^{*} \mathrm{P}<0.05$.

To avoid the formation of DNA-crosslinks, ICAD was added to the digest media. Fig 3 shows the improvement of islet yield following the addition of ICAD. For both the fully cannulated and half-cannulated pancreas, the optimal shaking time was shifted to $20 \mathrm{~min}$ with a further increased yield of $1,344 \pm 134$ and $1,286 \pm 124$ islets (Fig. 3A and B). One crucial improvement was that, following the optimal shaking time, the yield gradually decreased over a longer period of time; therefore, the addition of ICAD made the shaking procedure more controllable. For the non-cannulated pancreas, the effect of ICAD addition was not obvious; the optimal shake time remained at 20 min with $423 \pm 92$ islets (Fig. 3C).

Shaking procedures retain the biological activity and function of islets. Fresh islets were obtained following the shaking method. The majority of isolated islets were morphological intact with a well-defined surface, indicating the shaking procedure did not break the islets apart (Fig. 4). Almost none of the isolated islets exhibited a central necrotic zone, which suggested the islet condition in the shaking method group was consistent with the stationary method. Islets size distribution was also calculated and the findings indicated that the islets isolated via the stationary method has the same size distribution as the non-cannulated group, which had more larger islets than the fully-cannulated and half-cannulated groups subjected to the shaking method (Fig. 4).

Glucose challenge is an effective method for the study of islet functions in vitro prior to transplantation. The refraction index (high value/low value) represents insulin secretion ability via the islets' response to changes in blood glucose levels. As Fig 5 demonstrates, the refraction indices of all groups were $>2.5$, which indicated the well-preserved function of the isolated islets.

Transplantation of isolated islets with mechanical shaking successfully decreases the increased blood glucose levels of diabetic mice. Transplanted islets exhibited therapeutic effects after 1 day of transplantation and all diabetic mice became normoglycemic (Fig. 6). All the groups exhibited the same trend at the initial stage, but failed to control blood glucose 
A

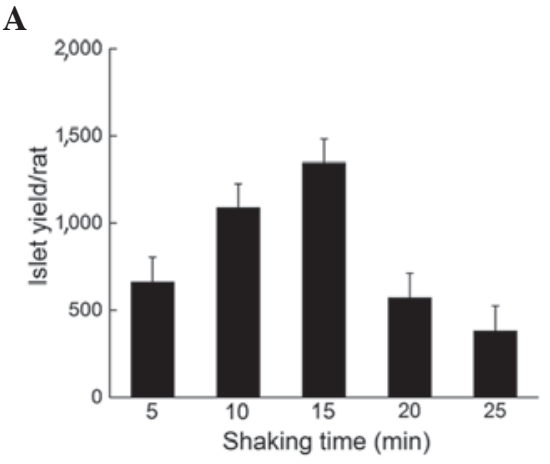

B

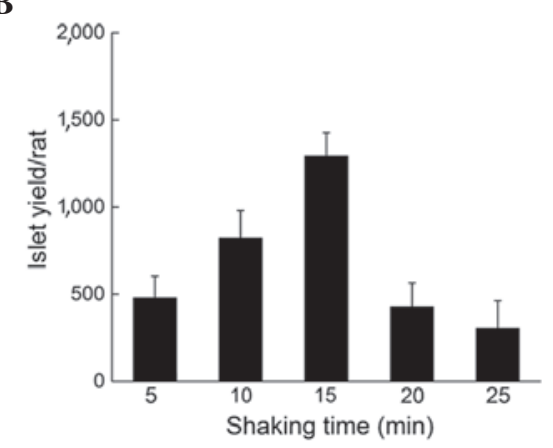

C

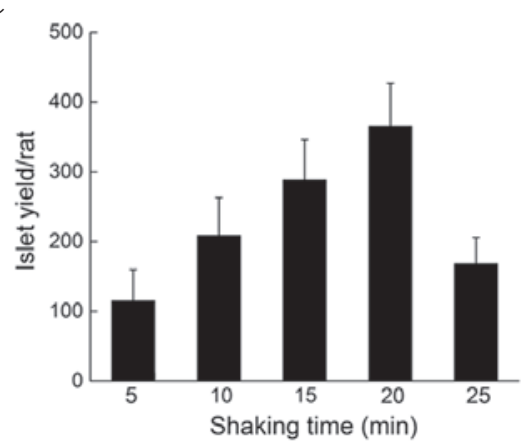

Figure 2. Islet yield of the shaking method with fully-cannulated, half-cannulated and non-cannulated treatment following the indicated incubation times. Islet yields from a single rat were compared following the shaking method, in which the pancreas was (A) fully-cannulated, (B) half-cannulated and (C) non-cannulated. Data are presented as the mean \pm standard deviation $(n=8)$.

A

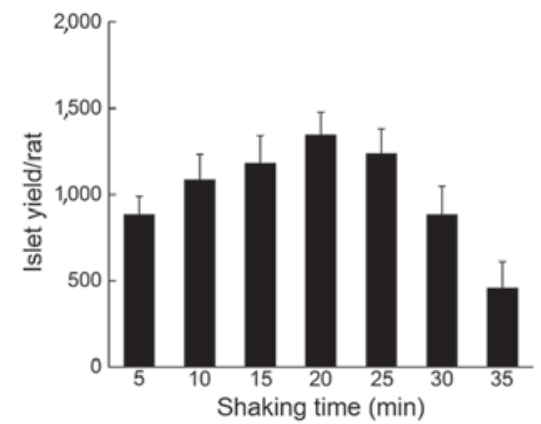

B

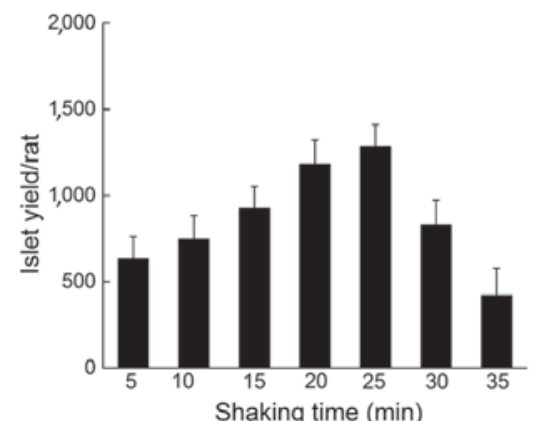

C

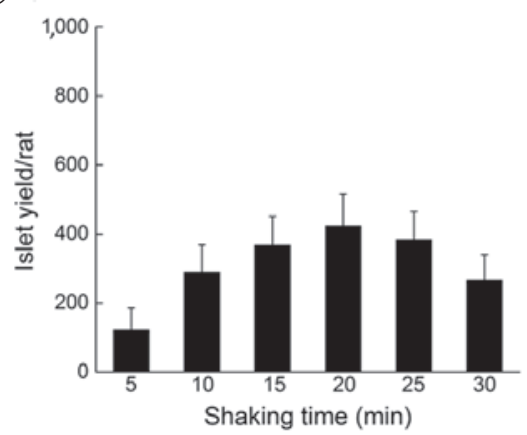

Figure 3. Islet yield of the shaking method in the presence of ICAD with fully-cannulated, half-cannulated and non-cannulated treatment following the indicated incubation times. Islet yields from a single rat were compared following the shaking method in the presence of ICAD, in which the pancreas was (A) fully-cannulated, (B) half-cannulated and (C) non-cannulated. Data are presented as the mean \pm standard deviation $(\mathrm{n}=8)$. ICAD, inhibitor of caspase-activated DNase.

A

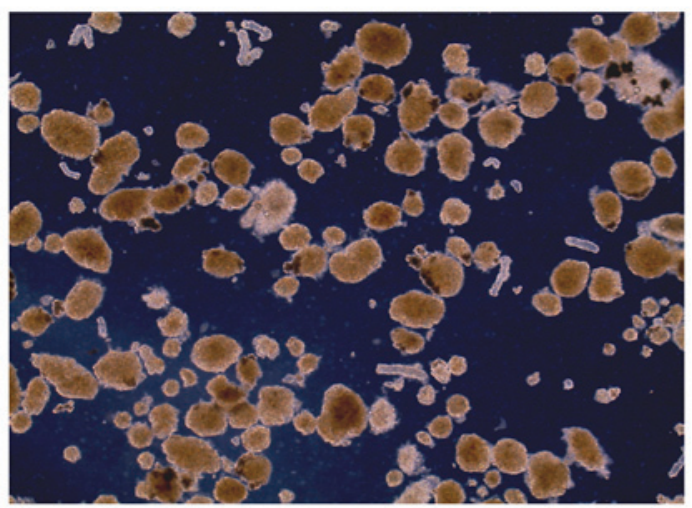

B

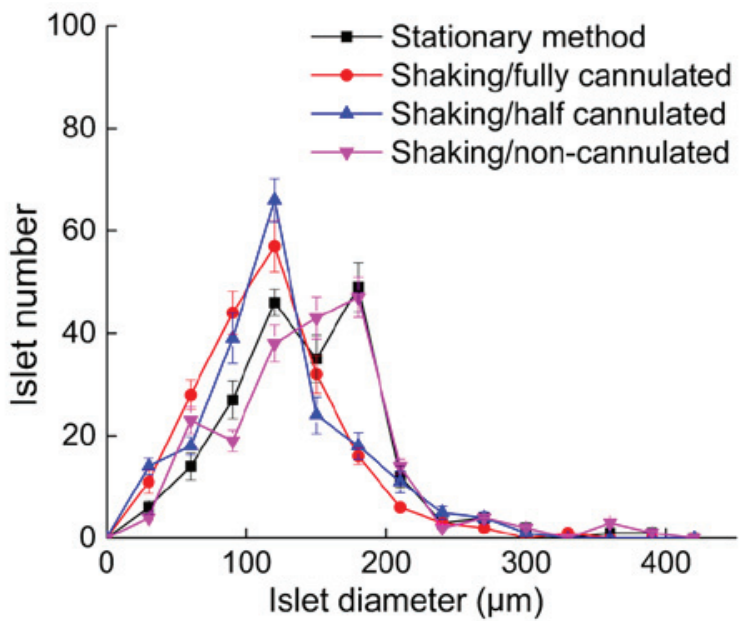

Figure 4. Fresh islets isolated with the facile mechanical shaking method and size distribution. (A) Typical fresh islets obtained via the shaking method. The majority of the isolated islets were morphologically intact with a well-defined surface (magnification, x20). (B) Islet size distribution was calculated and compared between the stationary and shaking methods, in which the pancreas was fully-cannulated, half-cannulated and non-cannulated, respectively. Data are presented as the mean \pm standard deviation $(n=8)$.

level after $\sim 7$ days of transplantation. Foreign body reactions or an immune response to xenografts may result in the death of transplanted islets. The present results indicated that greater numbers of islets can be isolated with the facile mechanical shaking method, and these islets also exhibited the normal function of decreasing blood glucose levels.

\section{Discussion}

The yield of islets isolation is crucial for islet transplantation in vivo (18). Though islets isolation methods have been extensively studied, the yield remains relatively low compared with the total islets isolated from a rat pancreas $(19,20)$. In the 


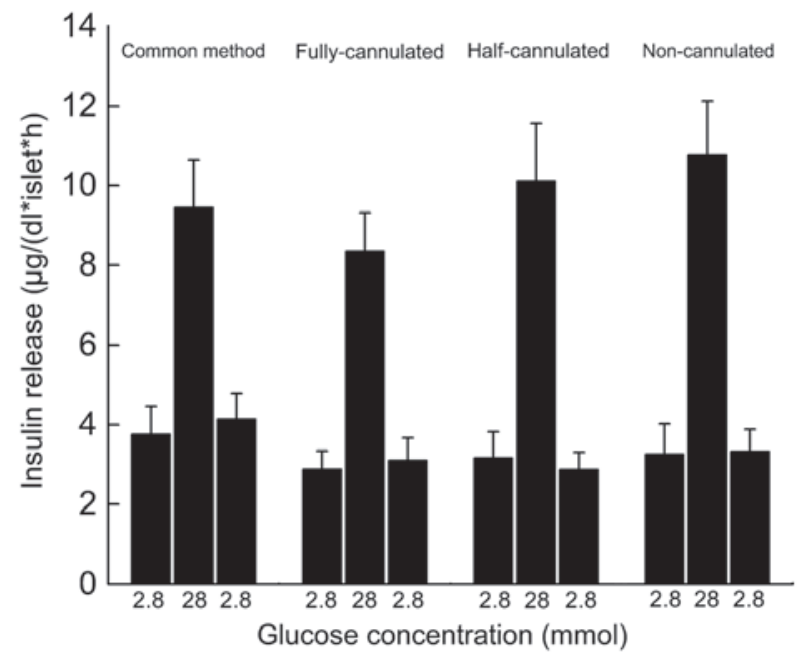

Figure 5. Glucose challenge of isolated islets in the different groups. Fresh islets were obtained following isolation via the stationary and shaking methods, in which the pancreas was fully-cannulated, half-cannulated and non-cannulated, respectively. Glucose challenge of the isolated islets was assayed and compared. Data are presented as the mean \pm standard deviation $(n=8)$.

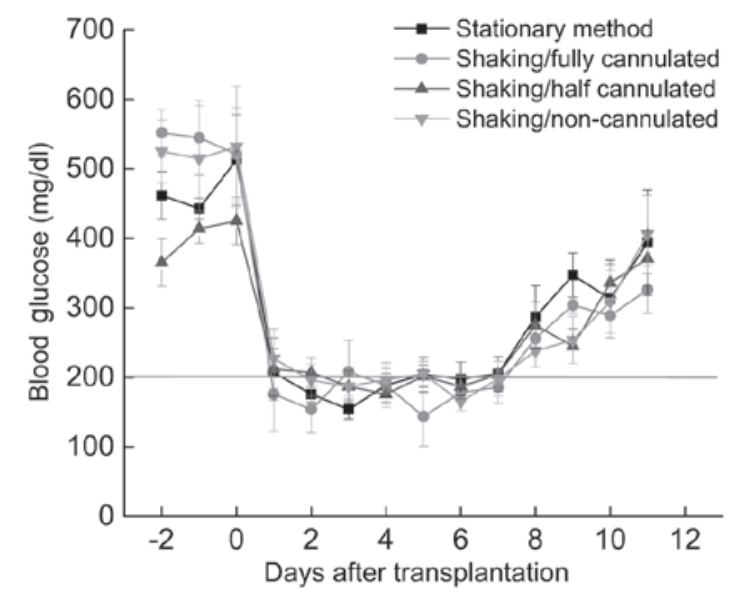

Figure 6. Therapeutic results of islet transplantation in the different groups. Fresh islets were obtained following isolation via the stationary and shaking methods, in which the pancreas was fully-cannulated, half-cannulated and non-cannulated, respectively. A total of 500 rat islets were injected into the abdominal cavity of mice, and the blood glucose levels of treated mice were monitored once every 2 days. Mice with blood glucose levels $<200 \mathrm{mg} / \mathrm{d}$ were considered normoglycemic. Monitoring continued until all mice had returned to a hyperglycemic state. Data are presented as the mean \pm standard deviation $(n=8)$.

present study, a facile mechanical shaking method was established, which improved the isolation yield to up to 1,600 islets per rat. Moreover, the islets exhibited well-preserved function to control blood glucose in vitro and in vivo. The present results provide an improved alternative isolation approach for islet preparation and transplantation in diabetes treatment.

Cannulation through the bile duct is paramount for islets isolation due to more comprehensive interaction between the pancreas tissue and digest media. However, successful cannulation required good cutting off of the ampulla site and careful handling of the syringe, as a minor error may cause enzyme media leakage to the surrounding tissue or duodenum, leading to the half-cannulated state (8). When cannulation was not adequate, particularly when the pancreas was removed without cannulation, it was difficult to harvest a large number of islets via the stationary method. Furthermore, large sections of tissue were not well-digested when the stationary technique was utilized. By studying the islets yield following various shaking times, the optimal procedure for different cannulation situations was elucidated. In addition, the present findings also indicated that the optimal shaking time for the non-cannulated pancreas was relatively longer than with the fully and half cannulated pancreas, which may be explained by the increased time required by the enzyme to digest the larger sections of tissue. Notably, a singular optimal shaking time point was not elucidated, as the pancreas states prior to digestion varied each time. The key point demonstrated by the present findings was that digestion should be monitored until the majority of the large sections of tissue have been digested into tiny sections, which ensure that they are able to precipitate at the bottom like sand.

In the present study, only 500-800 islets were successfully isolated from one rat pancreas via the well-established stationary method. Following the stationary digestion process, numerous islets were found to be attached to large sections of tissue. By drastically shaking the tissue in the tube, some of the islets were detached from the tissue. However, violent shaking may also cause islets to disintegrate (21). To solve this problem, instead of shaking after digestion, a continuous shaking protocol was applied during enzyme digestion. The results demonstrated that the shaking method resulted in an islet yield that was $\sim 2$ times greater than that of the stationary method. We hypothesize that the following aspects may contribute to this higher yield of rat islets: i) The digested enzyme had more comprehensive interaction with the pancreas tissue in the tube when shaking was applied, which means the enzyme can digest deeper into the tissue and disintegrate it more effectively, resulting in much smaller tissue sections compared with the stationary method (22); or ii) shaking during digestion provided a continuous and relatively gentle shear force to those islets exposed in the media (23). Islets may gradually detach from the tissue instead of becoming trapped deep into the undigested tissue, thus they are able to maintain their morphological integration.

Notably, obvious differences were observed for the different situations in which digestion occurred, when shaking was conducted for too long a time period. For example, tiny tissue sections were further digested, causing cell rupture and DNA release (data not shown) (24). Tiny tissue sections may undergo DNA crosslinking and become flocculent, which results in the tissue being unable to precipitate to the bottom of the sample being treated, inducing a huge decrease in the isolation yield (25). However, the same phenomenon was not observed in the non-cannulated pancreas since the digestion efficiency was relatively lower and individual cells did not rupture before the large tissue sections had been digested. Flocculent tissue forms due to the release of DNA and caspase-activated DNase subsequently breaks the DNA, which then acts as a cross-linker, and islets becomes trapped in the cross-linked tissue. A previous study has shown that the addition of the ICAD may help to avoid the effect of broken DNA (26). Shaking in the presence of ICAD attenuated the formation of cross-linked tissue. During the full and half 
cannulation protocols that required a more controlled shaking time, the addition of ICAD had a marked effect in that there was no flocculent tissue formed even following extended shaking times and instead, the tissue was further digested. This not only made the shaking procedure easier to control but also further increased the islet yields in the cannulated groups. However, for the non-cannulated groups, the islet yield was lower even in the presence of ICAD since the tissue size was larger and the enzyme may not have been able to reach the central tissue to rupture individual cells. Quantity and quality are usually mutually exclusive.

During the isolation progress, analysis of islet size distribution was conducted to determine if the continuous shear force was able to break islets apart. The present results indicated that there was a slight difference between the stationary technique and the non-cannulated method, which experienced less shear force in shaking and resulted in more large islets. Under a light microscope, the differences were difficult to recognize and islets from all methods were morphologically in good condition with a well-defined surface. Furthermore, it should be noted that bigger islets are not necessarily better, as previous culture and transplantation studies found that larger islets had a large necrotic zone when beta cells in the center experienced a low oxygen transport rate $(27,28)$. Glucose challenge was not only used to verify the viability of islets by studying the capability of islets to secret insulin response to various glucose levels, but it is also a critical in vitro experiment to predict the therapeutic efficiency of islets transplantation (29). The present results showed minimal differences between the islets isolated via the shaking and stationary methods, respectively, which have already been proven to exhibit good therapeutic efficiency when transplanted. The high reflection index indicated a sufficient amount of insulin would be secreted by islets isolated via the shaking method when blood glucose level raise. Islet transplantation has been demonstrated to be the most promising approach to elucidating a cure for type 1 diabetics and it may also be a direct way to verify the in vivo activity of isolated islets (30). The intraperitoneal cavity has been shown to be one of best transplantation sites, where nutrition and oxygen are abundant (31). Blood glucose levels exhibited the same trend for all the protocols, and xenograft islets were able to control the blood glucose levels of diabetic mice following transplantation. Viability persisted for approximately one week, which was consistent with the findings of previous studies $(32,33)$.

The present study described a facile mechanical shaking method for the high isolation efficiency of rat islets. In the presence of rat ICAD, the isolation yield could reach as high as 1,600 islets per rat, which was $55 \%$ more than the current well-established stationary method. In vitro tests demonstrated that isolated islets were morphologically intact and had well-preserved function in response to blood glucose alterations, and the transplantation of isolated islets successfully reversed the blood glucose levels of diabetic mice for a week. With this facile mechanical shaking method, islet transplantation studies conducted with rats in the laboratory should be more effective. In addition, this method may be applied in human islet isolation and could potentially improve the efficiency of clinical islet therapy.

\section{References}

1. Lakey JR, Burridge PW and Shapiro AM: Technical aspects of islet preparation and transplantation. Transpl Int 16: 613-632, 2003.

2. Matsumoto S, Okitsu T, Iwanaga Y, Noguchi H, Nagata H, Yonekawa Y, Yamada Y, Fukuda K, Tsukiyama K, Suzuki H, et al: Insulin independence after living-donor distal pancreatectomy and islet allotransplantation. Lancet 365: 1642-1644, 2005.

3. Matsumoto S, Okitsu T, Iwanaga Y, Noguchi H, Nagata H, Yonekawa Y, Yamada Y, Fukuda K, Shibata T, Kasai Y, et al: Successful islet transplantation from nonheartbeating donor pancreata using modified Ricordi islet isolation method. Transplantation 82: 460-465, 2006.

4. Khan KM, Desai CS, Kalb B, Patel C, Grigsby BM, Jie T, Gruessner RW and Rodriguez-Rilo H: MRI prediction of islet yield for autologous transplantation after total pancreatectomy for chronic pancreatitis. Dig Dis Sci 58: 1116-1124, 2013.

5. Lacy PE and Kostianovsky M: Method for the isolation of intact islets of Langerhans from the rat pancreas. Diabetes 16: 35-39, 1967.

6. Miyazaki J, Araki K, Yamato E, Ikegami H, Asano T, Shibasaki Y, Oka Y and Yamamura K: Establishment of a pancreatic beta cell line that retains glucose-inducible insulin secretion: Special reference to expression of glucose transporter isoforms. Endocrinology 127: 126-132, 1990.

7. Sutherland DE, Radosevich DM, Bellin MD, Hering BJ, Beilman GJ, Dunn TB, Chinnakotla S, Vickers SM, Bland B, Balamurugan AN, et al: Total pancreatectomy and islet autotransplantation for chronic pancreatitis. J Am Coll Surg 214: 409-424; discussion 424-426, 2012.

8. Li DS, Yuan YH, Tu HJ, Liang QL and Dai LJ: A protocol for islet isolation from mouse pancreas. Nat Protoc 4: 1649-1652, 2009.

9. Soltani SM, O'Brien TD, Loganathan G, Bellin MD, Anazawa T, Tiwari M, Papas KK, Vickers SM, Kumaravel V, Hering BJ, et al: Severely fibrotic pancreases from young patients with chronic pancreatitis: Evidence for a ductal origin of islet neogenesis. Acta Diabetol 50: 807-814, 2013.

10. Jin SM, Oh SH, Kim SK, Jung HS, Choi SH, Jang KT, Lee KT, Kim JH, Lee MS, Lee MK and Kim KW: Diabetes-free survival in patients who underwent islet autotransplantation after $50 \%$ to $60 \%$ distal partial pancreatectomy for benign pancreatic tumors. Transplantation 95: 1396-1403, 2013.

11. Goto T, Tanioka Y, Sakai T, Terai S, Kamoda Y, Li S, Tanaka T, Tsujimura T, Matsumoto I, Fujino Y, et al: Application of the two-layer method on pancreas digestion results in improved islet yield and maintained viability of isolated islets. Transplantation 83: 754-758, 2007.

12. Machida T, Tanemura M, Ohmura Y, Tanida T, Wada $H$, Kobayashi S, Marubashi S, Eguchi H, Ito T, Nagano $\mathrm{H}$, et al: Significant improvement in islet yield and survival with modified ET-Kyoto solution: ET-Kyoto/Neutrophil elastase inhibitor. Cell Transplant 22: 159-173, 2013.

13. Ito T, Chen D, Chang CW, Kenmochi T, Saito T, Suzuki S and Takemoto JY: Mesobiliverdin IX $\alpha$ enhances rat pancreatic islet yield and function. Front Pharmacol 4: 50, 2013.

14. de Haan BJ, Faas MM, Spijker H, van Willigen JW, de Haan A and de Vos P: Factors influencing isolation of functional pancreatic rat islets. Pancreas 29: e15-e22, 2004.

15. Enari M, Sakahira H, Yokoyama H, Okawa K, Iwamatsu A and Nagata S: A caspase-activated DNase that degrades DNA during apoptosis, and its inhibitor ICAD. Nature 391: 43-50, 1998.

16. Zhang $\mathrm{J}$ and $\mathrm{Xu} \mathrm{M}$ : Apoptotic DNA fragmentation and tissue homeostasis. Trends Cell Biol 12: 84-89, 2002.

17. Kim YH, Wee YM, Choi MY, Lim DG, Kim SC and Han DJ: Interleukin (IL)-10 induced by CD11b(+) cells and IL-10-activated regulatory $\mathrm{T}$ cells play a role in immune modulation of mesenchymal stem cells in rat islet allografts. Mol Med 17: 697-708, 2011.

18. Najjar M, Manzoli V, Abreu M, Villa C, Martino MM, Molano RD, Torrente Y, Pileggi A, Inverardi L, Ricordi C, et al: Fibrin gels engineered with pro-angiogenic growth factors promote engraftment of pancreatic islets in extrahepatic sites in mice. Biotechnol Bioeng 112: 1916-1926, 2015.

19. Attia AA: Histological and electron microscopic studies of the effect of beta-carotene on the pancreas of streptozotocin (STZ)-induced diabetic rats. Pak J Biol Sci 12: 301-314. 2009.

20. Chen Y, Hong F, Chen H, Fan RF, Zhang XL, Zhang Y and Zhu JX: Distinctive expression and cellular distribution of dopamine receptors in the pancreatic islets of rats. Cell Tissue Res 357: 597-606, 2014. 
21. Klaffschenkel RA, Waidmann M, Northoff H, Mahmoud AA and Lembert N: PK11195, a specific ligand of the peripheral benzodiazepine receptor, may protect pancreatic beta-cells from cytokine-induced cell death. Artif Cells Blood Substit Immobil Biotechnol 40: 56-61, 2012.

22. Shimoda M, Noguchi H, Fujita Y, Takita M, Ikemoto T, Chujo D, Naziruddin B, Levy MF, Kobayashi N, Grayburn PA and Matsumoto S: Islet purification method using large bottles effectively achieves high islet yield from pig pancreas. Cell Transplantat 21: 501-508, 2012.

23. Silva PN, Green BJ, Altamentova SM and Rocheleau JV: A microfluidic device designed to induce media flow throughout pancreatic islets while limiting shear-induced damage. Lab Chip 13: 4374-4384, 2013

24. Itoh T, Takita M, SoRelle JA, Shimoda M, Sugimoto K, Chujo D, Qin H, Naziruddin B, Levy MF and Matsumoto S: Correlation of released HMGB1 levels with the degree of islet damage in mice and humans and with the outcomes of islet transplantation in mice. Cell Transplant 21: 1371-1381, 2012.

25. Deans AJ and West SC: DNA interstrand crosslink repair and cancer. Nat Rev Cancer 11: 467-480, 2011.

26. Yamamoto-Tanaka M, Makino T, Motoyama A, Miyai M, Tsuboi R and Hibino T: Multiple pathways are involved in DNA degradation during keratinocyte terminal differentiation. Cell Death Dis 5: e1181, 2014.

27. Barkai U, Weir GC, Colton CK, Ludwig B, Bornstein SR Brendel MD, Neufeld T, Bremer C, Leon A, Evron Y, et al: Enhanced oxygen supply improves islet viability in a new bioartificial pancreas. Cell Transplantat 22: 1463-1476, 2013.
28. Henriksnäs J, Lau J, Zang G, Berggren PO, Köhler M and Carlsson PO: Markedly decreased blood perfusion of pancreatic islets transplanted intraportally into the liver: Disruption of islet integrity necessary for islet revascularization. Diabetes 61: 665-673, 2012 .

29. Szkudelski T: Streptozotocin-nicotinamide-induced diabetes in the rat. Characteristics of the experimental model. Exp Biol Med (Maywood) 237: 481-490, 2012.

30. Sakata N, Sumi S, Yoshimatsu G, Goto M, Egawa S and Unno M Encapsulated islets transplantation: Past, present and future. World J Gastrointest Pathophysiol 3: 19-26, 2012.

31. Bruni A, Gala-Lopez B, Pepper AR, Abualhassan NS and Shapiro AJ: Islet cell transplantation for the treatment of type 1 diabetes: Recent advances and future challenges. Diabetes Metab Syndr Obes 7: 211-23, 2014.

32. Caballero F, Siniakowicz K, Hollister-Lock J, Duran L, Katsuta H, Yamada T, Lei J, Deng S, Westermark GT, Markmann J, et al: Birth and death of human $\beta$-cells in pancreases from cadaver donors, autopsies, surgical specimens, and islets transplanted into mice. Cell Transplant 23: 139-151, 2014.

33. Yang SB, Lee HY, Young DM, Tien AC, Rowson-Baldwin A, Shu YY, Jan YN and Jan LY: Rapamycin induces glucose intolerance in mice by reducing islet mass, insulin content and insulin sensitivity. J Mol Med (Berl) 90: 575-585, 2012. 